\title{
Anesthetic experience using extracorporeal membrane oxygenation for cesarean section in the patient with peripartum cardiomyopathy
}

\section{-a case report-}

\author{
Han-Young Kim, Hyung-Joon Jeon ${ }^{1}$, Ji-Hyun Yun ${ }^{1}$, Jong-Hyuk Lee ${ }^{2}$, Gang-Geon Lee ${ }^{1}$, and \\ Seong-Chang Woo ${ }^{1}$ \\ Department of Anesthesiology and Pain Medicine, ${ }^{1}$ Eulji University Hospital, Daejeon, ${ }^{2}$ Asan Medical Center, University of Ulsan \\ College of Medicine, Seoul, Korea
}

Peripartum cardiomyopathy is a rare form of cardiomyopathy that is associated with significant mortality. It can cause a cardiac arrest during cesarean section even though the patient does not have any previous symptom and sign. The most important thing of anesthesia in this patient is an optimization of hemodynamic and respiratory status. We report the successful general anesthesia using of extracorporeal membrane oxygenation for cesarean section in a 34-year-old woman with fulminant peripartum cardiomyopathy. (Korean J Anesthesiol 2014; 66: 392-397)

Key Words: Extracorporeal membrane oxygenation, General anesthesia, Peripartum cardiomyopathy.

Peripartum cardiomyopathy (PPCM) is a type of dilated cardiomyopathy which occurs from the last month of pregnancy to 5 months after childbirth without any specific cause [1]. Dyspnea, fatigue, and peripheral edema can frequently occur during the later stages of normal pregnancy, so the symptoms of PPCM are hidden and it is difficult to make an early diagnosis [1-3]. Occurrence of PPCM is quite rare [1-5], but mortality reaches 20-80\% [4]. The authors experienced a case in which a 34-yearold multipara developed severe dyspnea and hemoptysis from PPCM during pregnancy at 37 weeks and 3 days. It was difficult to maintain the pregnancy any further, or perform spinal anes- thesia or epidural anesthesia. To optimize the subsequent treatment and pulmonary function and hemodynamic state during surgery, extracorporeal membrane oxygenation (ECMO) was used during general anesthesia for a cesarean section. We report this case together with a literature review.

\section{Case Report}

A 34-year-old multipara at 37 weeks and 3 days of pregnancy visited the ER complaining of low abdominal pain, nausea, and vomiting which started earlier in the morning. The patient was

Received: March 26, 2013. Revised: April 24, 2013. Accepted: April 29, 2013.

Corresponding author: Seong-Chang Woo, M.D., Ph.D., Department of Anesthesiology and Pain Medicine, Eulji University Hospital, 1306, Seo-gu, Dunsan-dong, Daejeon 302-120, Korea. Tel: 82-42-611-3655, Fax: 82-42-611-3882, E-mail: woonoh@eulji.ac.kr

(c)This is an open-access article distributed under the terms of the Creative Commons Attribution Non-Commercial License (http:// creativecommons.org/licenses/by-nc/3.0/), which permits unrestricted non-commercial use, distribution, and reproduction in any medium, provided the original work is properly cited. 
$157 \mathrm{~cm}$ in height and weighed $67 \mathrm{~kg}$, and weight gain during the pregnancy was $13 \mathrm{~kg}$. Parity was $1-0-0-1$, and there were no abnormalities in her past medical history. At the time of admittance, her blood pressure was 120/75 $\mathrm{mmHg}$, heart rate 75 beats/ $\mathrm{min}$, and respiratory rate $22 \mathrm{times} / \mathrm{min}$. The chest radiography was normal, but overall ST segment depression was observed in the electrocardiography, and the troponin-T figures on the lab test were increased to $0.206 \mathrm{ng} / \mathrm{ml}$. CK-MB figures were normal at $3.52 \mathrm{ng} / \mathrm{ml}$, and there were no other abnormalities in the lab test. According to a non-stress test, the fetal heart rate was 130 beats/min.

One hour after admittance, her blood pressure increased to $158 / 100 \mathrm{mmHg}$ and sinus tachycardia of 124 beats/min was observed. According to the echocardiography, the size of the left ventricle was normal, but there was a moderate decline in systolic function accompanied by a decrease in overall wall motion. In addition, moderate mitral regurgitation, tricuspid regurgitation, and pulmonary hypertension were observed. The left ventricular ejection fraction (LVEF) was 39\%, left ventricular end diastolic dimension (LVEDD) was $5.2 \mathrm{~cm}$, and left ventricular end systolic dimension (LVESD) was $4.3 \mathrm{~cm}$. The patient was transferred to intensive care under suspicion of peripartum cardiomyopathy (PPCM). When entering the intensive care, her blood pressure was 149/100 $\mathrm{mmHg}$, heart rate 110 beats/min, and respiration rate 27 times/min. Three hours after entering the intensive care unit (ICU), the patient suddenly started to complain of hemoptysis and dyspnea, so oxygen was provided through a nasal prong at $4 \mathrm{~L} / \mathrm{min}$. On the chest radiograph, severe pulmonary edema was observed in both lungs (Fig. 1). Furosemide $20 \mathrm{mg}$ and nitroglycerin $8 \mu \mathrm{g} / \mathrm{min}$ were injected but there was no improvement in her symptoms, so furosemide

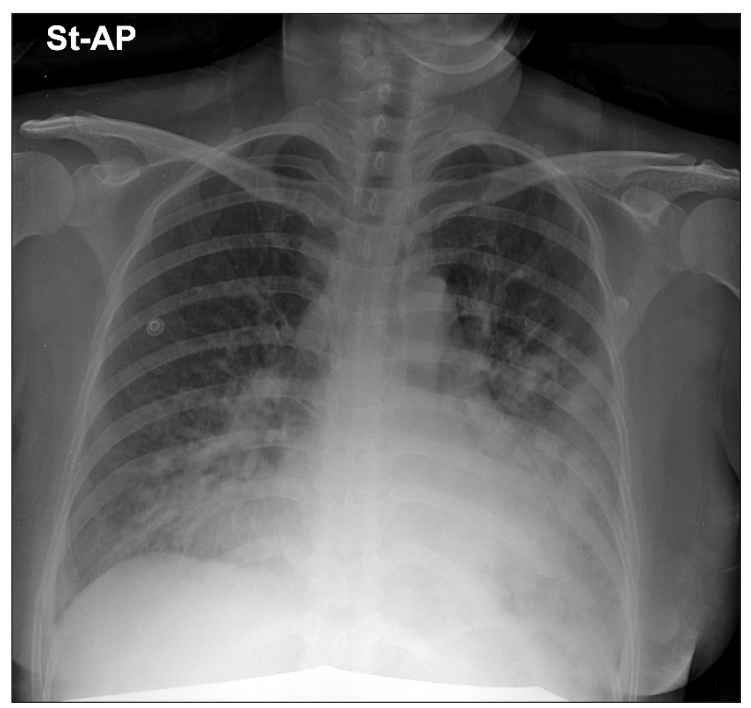

Fig. 1. The preoperative chest X-ray showing pulmonary edema.
$20 \mathrm{mg}$ was additionally used and nitroglycerin was increased to $12 \mu \mathrm{g} / \mathrm{min}$. Oxygen was supplied through a mask at $10 \mathrm{~L} / \mathrm{min}$. According to the arterial blood gas analysis (ABGA), her blood $\mathrm{pH}$ was 7.4, $\mathrm{PaCO}_{2} 16.1 \mathrm{mmHg}, \mathrm{PaO}_{2} 62 \mathrm{mmHg}, \mathrm{BE}-8.7 \mathrm{mEq} / \mathrm{L}$, and $\mathrm{SaO}_{2} 91 \%$. On the non-stress test, the fetal heart rate had increased to 180 beats/min and fetal distress was anticipated; thus, it was decided to perform a cesarean section for the safety of the fetus and the treatment of the patient. Before anesthesia, the patient was visited in the ICU to determine the state of the patient. The patient showed severe dyspnea, orthopnea, and hemoptysis. Her blood pressure was 130/98 $\mathrm{mmHg}$, heart rate 128 beats/min, and respiratory rate 45 times/min. Sinus tachycardia was observed in the electrocardiogram (ECG). Due to the severe dyspnea and hemoptysis which worsened when lying down, the patient could not assume a supine position so it was impossible to perform spinal or epidural anesthesia. Hence, it was decided to perform a cesarean section under general anesthesia. To assist the patient's state during surgery, installation of an ECMO was attempted before surgery but it failed because the patient could not maintain a supine position. Thus, it was decided to install the ECMO under general anesthesia and perform the cesarean section.

When the patient arrived at the operating room, she was receiving oxygen $10 \mathrm{~L} / \mathrm{min}$ through a mask and nitroglycerin $12 \mu \mathrm{g} / \mathrm{min}$ through an IV. Monitoring was started with an ECG, noninvasive blood pressure monitor, and pulse oximeter, and a catheter was inserted in the right radial artery for continuous monitoring of blood pressure and ABGA. Before induction of anesthesia, her blood pressure was $135 / 98 \mathrm{mmHg}$, heart rate 130 beats/min, and peripheral oxygen saturation 98\%. According to the arterial blood gas analysis, blood $\mathrm{pH}$ was $7.40, \mathrm{PaCO}_{2} 22$ mmHg, $\mathrm{PaO}_{2} 82 \mathrm{mmHg}, \mathrm{BE}-9.3 \mathrm{mEq} / \mathrm{L}$, and $\mathrm{SaO}_{2}$ 96\%. Immediately before anesthesia, her induction blood pressure was 140/105 $\mathrm{mmHg}$ and her heart rate was 132 beats/min, and thiopental sodium $250 \mathrm{mg}$ was slowly injected to induce anesthesia in the sitting position. After checking loss of consciousness, succinylcholine $100 \mathrm{mg}$ was administered, and 40 seconds later, intubation was performed. Atracurium $40 \mathrm{mg}$ was additionally administered for muscle relaxation, and anesthesia was maintained with $100 \%$ oxygen and sevoflurane 2 vol\%. The ventilator was set for a tidal volume of $550 \mathrm{ml}$, respiration rate 16 times/ min, and positive-end expiratory pressure (PEEP) $5 \mathrm{cmH}_{2} \mathrm{O}$. Directly after intubation, her blood pressure was 155/110 $\mathrm{mmHg}$ and her heart rate was 138 beats/min. Sinus tachycardia was continually observed with the ECG, and anesthetic ABGA showed a blood pH 7.39, $\mathrm{PaCO}_{2} 24 \mathrm{mmHg}, \mathrm{PaO}_{2} 70 \mathrm{mmHg}, \mathrm{BE}$ $-9.2 \mathrm{mEq} / \mathrm{L}$, and $\mathrm{SaO}_{2}$ 93\%. Immediately after anesthesia, the ECMO (CAPIOX ${ }^{\circledR}$, Terumo Corp., Tokyo, Japan) was applied. A return canula (femoral arterial cannula FEMII016A, Edwards, Lifesciences Inc., Irvine, CA, USA) and drainage canula (femoral 
venous cannula VFEM022, Edwards, Lifesciences Inc., Irvine, CA, USA) were inserted in the left femoral artery and femoral vein, respectively. It took 20 minutes to complete the installation, and flow rate was maintained at $3 \mathrm{~L} / \mathrm{min}$. For a more accurate evaluation of preload and total body water during installation, a 8.5 Fr. central venous catheter (advanced venous access, AVA high flow device, Edwards, USA) was inserted in the internal jugular vein, and through this, we attempted to insert a SwanGanz catheter (Swan-Ganz CCOmbo 774HF75m, Edwards, USA). However, the ECMO was already operating at the time of the insertion of the Swan-Ganz catheter, so the catheter could only advance to the right ventricle. Hence, it failed to obtain an accurate pulmonary wedge pressure wave. During installation, the blood pressure of the patient was maintained at around 140-160/100-110 $\mathrm{mmHg}$, heart rate $120-130$ beats/min, peripheral oxygen saturation 91-95\%, and central venous pressure around 22-24 mmHg. After installing the ECMO, the ventilator setting was adjusted to a tidal volume of $400 \mathrm{ml}$, respiration rate 10 times/min, and $\mathrm{FiO}_{2}$ 0.5. Nitroglycerin was continually injected at speed of $12 \mu \mathrm{g} / \mathrm{min}$ throughout the surgery. The infant was delivered 5 minutes after starting the cesarean section. The APGA score of the infant was 3 and 4 at 1 minute and 5 minutes, and intubation was performed because the respiration of the infant was weak. After delivery, oxytocin 40 units was mixed with normal saline $100 \mathrm{ml}$ and slowly injected, and $500 \mathrm{ml}$ of colloid solution was administered. There was no great change in blood pressure during the cesarean section, and a mean pressure was maintained at around $100-120 \mathrm{mmHg}$, heart rate at 100 beats/min, peripheral oxygen saturation at $100 \%$, and central venous pressure at around 14-18 $\mathrm{mmHg}$. ABGA showed a blood pH 7.38, $\mathrm{PaCO}_{2} 24.6 \mathrm{mmHg}, \mathrm{PaO}_{2} 408 \mathrm{mmHg}, \mathrm{BE}-11 \mathrm{mEq} / \mathrm{L}$, and $\mathrm{SaO}_{2}$ 100\%. Total operating time was 1 hour and $40 \mathrm{~min}$ utes, and total anesthetic time was 1 hour and 45 minutes. Total blood loss was $1,000 \mathrm{ml}$, and total fluid volume was $600 \mathrm{ml}$.

The patient was transferred to the ICU maintaining the ECMO and intubation. At the time of transfer, the mean blood pressure was $90-100 \mathrm{mmHg}$, heart rate 110 beats/min, and peripheral oxygen saturation $100 \%$. The ABGA showed a blood pH 7.31, $\mathrm{PaCO}_{2} 22 \mathrm{mmHg}, \mathrm{PaO}_{2} 359 \mathrm{mmHg}, \mathrm{BE}-13.2 \mathrm{mEq} /$ $\mathrm{L}$, and $\mathrm{SaO}_{2} 100 \%$. Three days after the operation, the blood pressure and wave of invasive arterial monitoring inserted in the right radial artery were relatively maintained, so the flow speed of the ECMO was decreased to $2 \mathrm{~L} / \mathrm{min}$. After decreasing the speed, the blood pressure of the patient was 95-120/79-95 $\mathrm{mmHg}$, heart rate $90-110$ beats/min, peripheral oxygen saturation $100 \%$, and central venous pressure 5-8 $\mathrm{mmHg}$. The ABGA showed a blood pH 7.5, $\mathrm{PaCO}_{2} 28 \mathrm{mmHg}, \mathrm{PaO}_{2} 508 \mathrm{mmHg}, \mathrm{BE}$ $0.8 \mathrm{mEq} / \mathrm{L}$, and $\mathrm{SaO}_{2} 100 \%$. Mechanical ventilation maintained a tidal volume of $400 \mathrm{ml}$, respiration rate 12 times/min, PEEP $3 \mathrm{cmH}_{2} \mathrm{O}$, and $\mathrm{FiO}_{2}$ 0.4. Four days after the operation, the flow speed of the ECMO was decreased to $1.3 \mathrm{~L} / \mathrm{min}$, and her blood pressure was 120-140/90-100 mmHg, heart rate 90-100 beats/ min, peripheral oxygen saturation $100 \%$, and central venous pressure 4-8 mmHg. The ABGA showed a blood $\mathrm{pH} 7.48$, $\mathrm{PaCO}_{2} 32 \mathrm{mmHg}, \mathrm{PaO}_{2} 517 \mathrm{mmHg}, \mathrm{BE} 0.6 \mathrm{mEq} / \mathrm{L}$, and $\mathrm{SaO}_{2}$ $100 \%$. Twelve hours later, the flow speed of the ECMO was decreased to $1 \mathrm{~L} / \mathrm{min}$, and there was no change in the blood pressure. Mechanical ventilation was maintained as before. Five days after the operation, her blood pressure was 110-140/80-100 $\mathrm{mmHg}$, heart rate $80-100$ beats/min, peripheral oxygen saturation $100 \%$, and central venous pressure $9 \mathrm{mmHg}$. The ABGA showed a blood pH 7.54, $\mathrm{PaCO}_{2} 28 \mathrm{mmHg}, \mathrm{PaO}_{2} 639 \mathrm{mmHg}$, BE $1.8 \mathrm{mEq} / \mathrm{L}$, and $\mathrm{SaO}_{2} 100 \%$. The waveform on the invasive arterial monitoring was well maintained, and wall movement of the left ventricle was observed to be relatively adequate in the ECG. The ECMO was removed, and after the removal, her blood pressure was 94-104/66-70 mmHg, heart rate 100 beats/ min, peripheral oxygen saturation $100 \%$, and central venous pressure 5-7 mmHg. The ABGA showed a blood $\mathrm{pH} 7.4, \mathrm{PaCO}_{2}$ $28 \mathrm{mmHg}, \mathrm{PaO}_{2} 639 \mathrm{mmHg}, \mathrm{BE} 1.8 \mathrm{mEq} / \mathrm{L}$, and $\mathrm{SaO}_{2} 100 \%$. Dopamine was injected at speed of $5 \mu \mathrm{g} / \mathrm{kg} / \mathrm{min}$. Seven days after the operation, mechanical ventilation was removed and the patient was transferred to a general ward. At the time of transfer, her blood pressure was 100-130/65-70 $\mathrm{mmHg}$ and heart rate 75-90 beats/min. The ABGA showed a blood $\mathrm{pH} 7.42, \mathrm{PaCO}_{2}$ $43 \mathrm{mmHg}, \mathrm{PaO}_{2} 156 \mathrm{mmHg}, \mathrm{BE} 2.9 \mathrm{mEq} / \mathrm{L}$, and $\mathrm{SaO}_{2} 98 \%$. The ECG was normal and the pulmonary edema was also greatly improved in the chest radiograph. On the echocardiograph, the LVEF was $58 \%$ so the systolic function of the left ventricle was corrected, and only a slight mitral regurgitation was observed.

The infant was transferred to a neonate intensive care unit while maintaining intubation. Based on the babygram taken, there were no abnormalities, and extubation was performed 2 days later. There were no abnormalities in the abdominal sonography taken 2 days after birth, and brain ischemia caused by hypoxia was not observed in the brain MRI. The infant was discharged 11 days after hospitalization.

\section{Discussion}

PPCM is a form of heart failure which can occur during pregnancy or after childbirth, and it is a very rare condition which occurs in 1 in 15,000 deliveries [5]. To be diagnosed with PPCM, four diagnostic criteria are required. First is the occurrence of heart failure caused by decreased systolic function of the left ventricle within the last month of pregnancy to 5 months after childbirth. Second is that there are no abnormalities in cardiac function previously, and third is that there is no clear cause for the cardiomyopathy. Fourth is that there is one or more observations of either LVEF in echocardiograph at $45 \%$ or lower or 
M-mode fractional shortening at 30\% or lower, and LVEDD is $2.7 \mathrm{~cm} / \mathrm{m}^{2}$ or higher [1-5]. Mitral infarction, sepsis, severe preeclampsia, amniotic fluid embolism, and pulmonary embolism should be considered in the differential diagnosis [2].

The etiology of PPCM has not yet been identified, as can be seen in the diagnosis criteria $[1,2,3,5]$. Only the risk factors are considered to be multiparity: the age of the mother (30 or higher), multifetal pregnancy, pre-eclampsia, gestational hypertension, and black race [1-3]. A diverse range for mortality from 20 to $80 \%$ has been reported, and it has been reported that left ventricle function recovered in $50 \%$ of surviving patients [4].

Early diagnosis is important for successful treatment of PPCM. When diagnosis is delayed, there is greater possibility of symptom aggravation and death [1]. However, early diagnosis is difficult because the initial symptoms of PPCM, such as dyspnea, fatigue, and peripheral edema, are similar to the normal symptoms of late stage pregnancy [1-3]. In the physical examination, tachycardia, tachypnea, and increased or decreased blood pressure, increased jugular venous pressure, displaced apical impulse, murmurs of mitral and tricuspid regurgitation, pulmonary rale, and peripheral edema are observed [2,3]. Generally, sinus tachycardia and nonspecific ST segment change are observed in the ECG [2,3], and cardiomegaly, pulmonary venous congestion, or pulmonary edema is observed in the chest radiograph [3]. In the echocardiograph, left ventricular dilatation to various degrees, moderate to severe left ventricular systolic function, pulmonary arterial pressure, and mild pulmonary regurgitation are observed [3].

Echocardiograph plays an important role in the diagnosis of PPCM as well as in the evaluation of the prognosis. At the time of diagnosis, if LVEF is larger than $27 \%$ or LVESD is $5.5 \mathrm{~cm}$ or lower, it is reported that there is an increased possibility of recovering left ventricle function [6]. In our case, the LVEF of the patient was $39 \%$ and LVESD was $4.3 \mathrm{~cm}$ at the initial diagnosis, so left ventricle function was expected to return to normal.

Drug treatment for PPCM is similar to treatment for other forms of heart failure. Drugs such as diuretics, vasodilators, inotropes, ACE inhibitors, ARB, and beta-blockers can be used [1-3]. However, when PPCM occurs during pregnancy, as in our case, the influence of drugs on the fetus must be considered. For example, ACE inhibitors and ARB may cause deformities such as renal tubular dysplasia, so it cannot be used. In addition, the possibility of thromboembolic complications during pregnancy increases, so anticoagulation treatment must be considered [1-3]. There are reports that there was a positive effect when pentoxifylline, immunoglobulin, immunosuppressive therapy, and bromocriptine were used in treatment, and when there is no response to the medication, more invasive treatment such as cardiac assist devices and cardiac transplantation can be considered $[1,3]$.

The hemodynamic purpose in cesarean anesthesia of PPCM patients is to reduce the preload and afterload of the heart, and prevent the decline of the already-reduced cardiac contractility $[7,8]$. Regardless of the anesthesia method or drug, sudden decline of systemic vascular resistance should be avoided, and appropriate anesthesia methods and careful drip of the medication according to the situation are important [7]. Invasive monitoring is recommended to maintain hemodynamic stability $[7,8]$. The respiration of the fetus is conducted through gas exchange of oxygen and carbon dioxide through the placenta, so it relies entirely on the mother. Thus, maternal blood gas concentration, uterine blood supply, and the degree of gas exchange between the placenta and fetus play an important role [9]. Therefore maintaining the appropriate ventilation and oxygenation in PPCM mothers is important for the fetus as well as the mother. In various cases, general anesthesia and regional anesthesia such as spinal anesthesia, epidural anesthesia, and combined spinal epidural anesthesia were used [7,8,10-12]. In all cases which used regional anesthesia, it was explained that regional anesthesia regardless of the method had the advantage of avoiding hemodynamic stress from general anesthesia medication, and suppressed sympathetic tone and reduced preload and afterload to enhance ventricular function. In addition, the medication was slowly injected to prevent rapid decline of systemic vascular resistance, a disadvantage of regional anesthesia [10]. General anesthesia can be performed in an emergency cesarean section and when regional anesthesia is impossible, for example when patient cannot maintain a position for regional anesthesia due to dyspnea, or when taking anticoagulation drugs [7,10]. General anesthesia is advantageous in that maintenance of airway and ventilation can be controlled, but has the disadvantage of using a general anesthetic agent or rapid sequence induction can cause hemodynamic stress [10]. In cases using general anesthesia, propofol, etomidate and thiopentone were used as induction agents, and rocuronium and atracuronium were used as muscle relaxants. Propofol was continually injected, and thiopentone was slowly drip injected, and there were no cases showing great hemodynamic instability during anesthesia $[8,11,12]$. In addition, there were cases that obtained appropriate hemodynamic stability in anesthesia induction and maintenance by using remifentanil in general anesthesia to reduce stress $[11,12]$. In our case, general anesthesia was selected as the anesthesia method for our patient. The reason was spinal anesthesia or epidural anesthesia could not be performed because the patient could not maintain a supine position due to severe dyspnea and occurrence of severe hemoptysis when lying down.

ECMO is used to assist gas exchange and cardiac function when there is severe respiratory failure or heart failure $[13,14]$. It is used in post-cardiotomy, post-heart transplant, and in severe heart failure due to cardiomyopathy, myocarditis, and acute coronary syndrome, as well as in respiratory distress due to adult 
respiratory distress syndrome, pneumonia, trauma, and primary graft failure. It can also be used in assisting respiration in neonatal and pediatric respiratory failure [14]. ECMO receives the vein through the catheter and uses the pump to move the blood to the membrane oxygenator. The membrane oxygenator removes the carbon dioxide and supplies oxygen, and then the blood is sent back to the body through the catheter. Here, when the blood moves to the vein, it becomes the form of venovenous (VV) ECMO, and when it moves to the artery, it becomes venoarterial (VA) ECMO. VV ECMO is used in respiratory failure, while VA ECMO can be used in respiratory failure and heart failure $[13,14]$. VA ECMO used in this case bypasses the ventricles and lungs to perform the role of assisting pulmonary function and cardiac function. In other words, blood is moved to the membrane oxygenator through the return canula entering into the right atrium, and oxygen is supplied which reduces the amount of blood for the lung to exchange gas and reduce the load on the lungs. This reduces the amount of blood moving to the left ventricle, to play the role of reducing the preload of the left ventricle [13]. Additionally, after installing the ECMO, the oxygen concentration in the blood is not decided by the $\mathrm{FiO}_{2}$ or PEEP of the ventilator, but by the $\mathrm{FiO}_{2}$ and flow speed in the ECMO. The concentration of carbon dioxide is also decided not by the respiration rate of the ventilator, but by the flow speed in the ECMO. Therefore, after installing the ECMO, a low tidal volume and airway pressure and slower respiration rate can be used in mechanical ventilation, which prevents barotraumas from mechanical ventilation, reducing further damage to the lungs [14].

As explained above, the hemodynamic purpose in cesarean section anesthesia of PPCM patients is to reduce the preload and afterload, and prevent the decline of already reduced cardiac contractility $[7,8]$. Especially, immediately after delivery, the preload greatly increases due to womb contraction and autotransfusion, which can even lead to sudden death from cardiac overload in mothers with cardiac disorders [15]. In addition, gas exchange of the fetus is conducted completely through the placenta [9]; thus, it is important for both mother and child to maintain the appropriate ventilation and oxygenation in PPCM patients showing dyspnea symptoms. Hence, the authors used ECMO to assist pulmonary and hemodynamic function while performing general anesthesia for cesarean section for the following reasons: decline in cardiac function from PPCM, the possibility of cardiac arrest due to overload on the heart during surgery, and dyspnea from severe pulmonary edema.

In our case, the patient showed a LVEF of $27 \%$ in the echocardiograph performed 2 days after the operation and this is a smaller value compared to the value at the initial diagnosis. Rather than being caused by incorrect treatment after surgery, it is speculated that the LVEF of the patient was $27 \%$ or lower at the time of surgery, considering that the patient's symptoms had worsened immediately before surgery compared to at the time of initial diagnosis. In addition, the echocardiograph showed rapid improvement 5 days after the surgery.

We are reporting this case because ECMO was applied early during general anesthesia for cesarean section in a PPCM patient showing rapid deterioration. It was used to assist the reduced cardiac function and reduced pulmonary function caused by the severe pulmonary edema, and the surgery was successfully completed.

\section{References}

1. Ramaraj R, Sorrell VL. Peripartum cardiomyopathy: Causes, diagnosis, and treatment. Cleve Clin J Med 2009; 76: 289-96.

2. Abboud J, Murad Y, Chen-Scarabelli C, Saravolatz L, Scarabelli TM. Peripartum cardiomyopathy: a comprehensive review. Int J Cardiol 2007; 118: 295-303.

3. Elkayam U. Clinical characteristics of peripartum cardiomyopathy in the United States: diagnosis, prognosis, and management. J Am Coll Cardiol 2011; 58: 659-70.

4. Smith IJ, Gillham MJ. Fulminant peripartum cardiomyopathy rescue with extracorporeal membranous oxygenation. Int J Obstet Anesth 2009; 18: 186-8.

5. Yang HS, Hong YS, Rim SJ, Yu SH. Extracorporeal membrane oxygenation in a patient with peripartum cardiomyopathy. Ann Thorac Surg 2007; 84: 262-4.

6. Duran N, Günes H, Duran I, Biteker M, Ozkan M. Predictors of prognosis in patients with peripartum cardiomyopathy. Int J Gynaecol Obstet 2008; 101: 137-40.

7. Ramachandran R, Rewari V, Trikha A. Anaesthetic management of patients with peripartum cardiomyopathy. J Obstet Anaesth Cnt Care 2011; 1: 5-12.

8. Soni B, Gautam PL, Grewal A, Kaur H. Anaesthetic management of two cases of peripartum cardiomyopathy. J Obstet Anaesth Cnt Care 2011; 1: 41-5.

9. Bobrow CS, Soothill PW. Causes and consequences of fetal acidosis. Arch Dis Child Fetal Neonatal Ed 1999; 80: F246-9.

10. Bhakta P, Mishra P, Bakshi A, Langer V. Case report and mini literature review: anesthetic management for severe peripartum cardiomyopathy complicated with preeclampsia using sulfentanil in combined spinal epidural anesthesia. Yonsei Med J 2011; 52: 1-12. 
11. Bilehjani E, Kianfar AA, Fakhari MS. Anesthesia with etomidate and remifentanyl for cesarean section in severe peripartum cardiomyopathy. Rawal Med J 2008; 33: 109-11.

12. McCarroll CP, Paxton LD, Elliott P, Wilson DB. Using of remifentanil in a patient with peripartum cardiomyopathy requiring caesarean section. Br J Anaesth 2001; 86: 135-8.

13. Nichani S. An overview of extracorporeal membrane oxygenation (ECMO). Paediatr Child Health 2011; 21: 170-6.

14. Marasco SF, Lukas G, McDonald M, McMillan J, Ihle B. Review of ECMO (extracorporeal membrane oxygenation) support in critically ill adult patients. Heart Lung Circ 2008; 17 Suppl 4: S41-7.

15. Chandrasekhar S, Cook CR, Collard CD. Cardiac surgury in the parturient. Anesth Analg 2009; 108: 777-85. 